\title{
Keys for the Use of Ionic Liquids as Reaction Media in Enzyme-Catalyzed Processes
}

\section{Hernandez Fernandez FJ}

Department of Chemical and Environmental Engineering, Regional Campus of International Excellence, Technical University of Cartagena, Cartagena, Murcia, Spain

${ }^{*}$ Corresponding author: Hernandez Fernandez FJ, Department of Chemical and Environmental Engineering, Regional Campus of International Excellence, Technical University of Cartagena, Cartagena, Murcia, Spain, Tel: +34 868889112; E-mail: fj.herfer@upct.es

Received date: February 21, 2018; Accepted date: February 22, 2018; Published date: February 28, 2018

Copyright: (c) 2018 Fernandez FJH. This is an open-access article distributed under the terms of the Creative Commons Attribution License, which permits unrestricted use, distribution, and reproduction in any medium, provided the original author and source are credited.

\begin{abstract}
During recent years there has been a growing interest in the use of ionic liquids as substitutes for organic solvents. That has been due mainly to their unique properties, which highlight their very low volatility. This editorial is focus on analyzing the application of ionic liquids as reaction media in enzyme catalyzed reaction. Specifically, the advantages of using ionic liquids as reaction media for biocatalysts were discussed. Other considerations like green aspect of ionic liquids and the recovery of synthetic products from ionic liquid matrix were also analyzed.
\end{abstract}

Keywords: Ionic liquid; Biocatalysis; Green chemistry

\section{Introduction}

The interest in ionic liquids, often heralded as the green high-tech media of the future, is still increasing rapidly. Ionic liquids (ILs) are organic salts which are liquids under ambient temperature. They consist of an organic cation, and a polyatomic inorganic or organic anion. The structures of common cations and anions of ILs are shown in Figure 1.

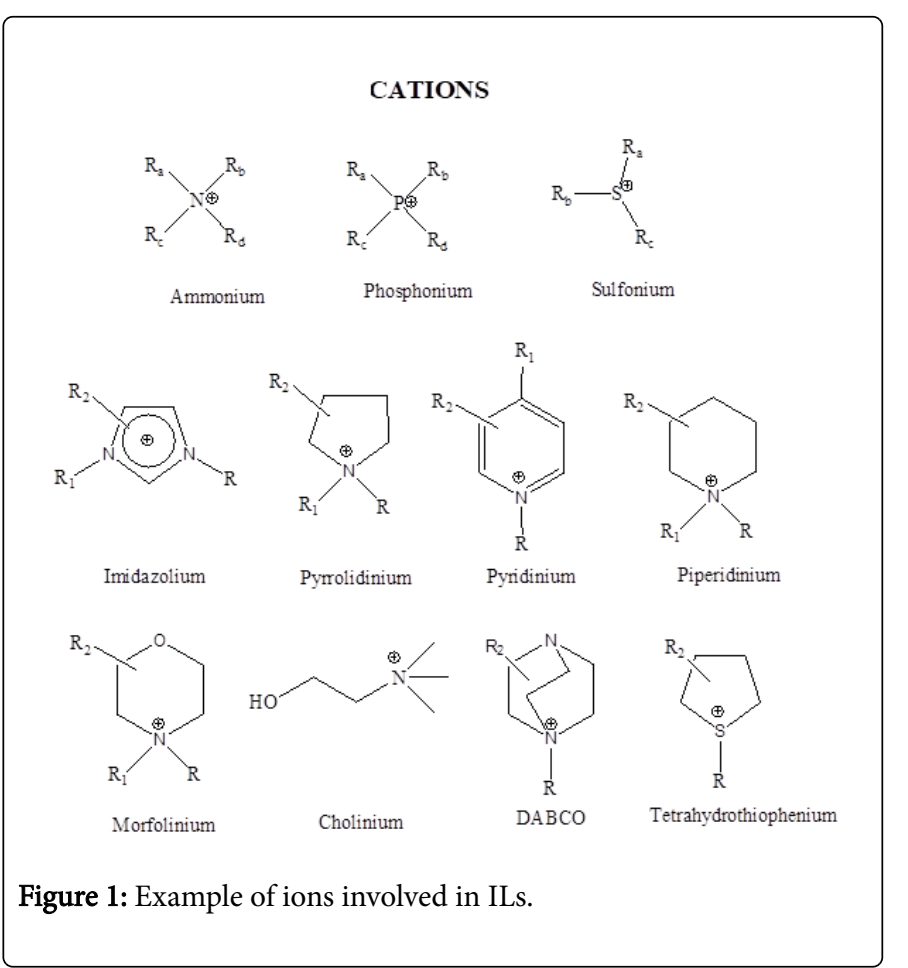

In addition, to avoiding the use of organic solvents and, thus, the emission of volatile compounds, the use of ionic liquids in enzymology has improved the activity, stability and selectivity of bio catalysis reactions in some cases. Consequently, ionic liquids have emerged as solvents for non-aqueous enzymology [1-6]. Here, we analyzed the keys for using ionic liquids on non-aqueous enzymology in a framework of green chemistry.

\section{The effect of ionic liquids on activity, selectivity and stability of enzymes}

Lipases, such as Candida antarctica lipase B (CaLB) [7-9], Pseudomonas cepacia lipase (PcL) and Candida rugosa lipase (CrL) $[10,11]$, have been the most used enzymes in ionic liquids. The ionic liquids have not only been applied in enzymatic reactions catalyzed by lipases but also others enzymes have been used in ionic liquids such as laccases [12-14] and penicillin G acylase [2].

An ionic liquid may play the same role as an organic solvent in affecting the enzyme performance by: (1) stripping off the essential water around the enzyme; (2) penetrating into the microaqueous phase to interact with the enzyme by modifying the protein dynamics, the protein conformation, and/or the enzyme's active site; and (3) interacting with the substrates and products by either reacting with them or by altering their partitioning between the aqueous and nonaqueous phases.

Consequently, the use of ionic liquids could affect positively or negatively the enzyme performance and specifically the enzyme activity, selectivity and stability. De los Ríos et al. [9] studied the effect of ionic liquids on activity, selectivity and stability of Candida antarctica lipase $\mathrm{B}(\mathrm{CaLB})$ for a trans esterification reaction. They found that the activity and stability is positively correlated with the ionic liquid hydrophobicity, which was explained by the fact that the increase in hydrophobicity of the medium could allow the preservation of the essential water layer around the protein molecule, thus reducing direct protein-ion interactions.

On the contrary, the selectivity was found to be correlated positively with the hydrophobicity of the ionic liquid due to his higher capacity of reducing water activity (Aw) in the enzyme microenvironment [9]. Similar behavior was observed for other enzymes such as lipase from Pseudomonas sp. (PsL), CrL, Subtilisin and Penicillin $G$ acylase 
[2,15-17]. It has been observed that, with few exceptions, enzyme activity and solubility in ionic liquids are mutually exclusive.

Very recently the ionic liquid choline dihydrogen phosphate [Chol] $\left[\mathrm{H}_{2} \mathrm{PO}_{4}\right]$ was found to allowed over-laccase activity. The ionic liquid [Chol] $\left[\mathrm{H}_{2} \mathrm{PO}_{4}\right]$ was seen to be very effective at enhancing and stabilizing the laccase activity, due to the modications in the secondary structure of the enzymatic protein [12].

\section{Green aspects of ionic liquids}

Regarding to the consideration of ionic liquids as green solvents, different degrees of toxicity have been reported from ILs compared to that of chemicals currently used as solvent in chemical industry, which could be explained by the enormous variety of ionic liquids [18].

The most important property of ionic, in contrast to conventional solvents, is their negligible vapour pressure. That can result in lower emissions and consequently in a reduced exposure. Other advantage of the ionic liquids is the possibility of designing more environmentally friendly ionic liquids with improved biocatalytic behavior properties by changing or modifying either the anion or cation.

These process intensification methodologies could reduce and even eliminate the dependence on volatile organic solvents.

\section{Isolation of reaction products from ionic liquids}

In order to get an integral green process, it is necessary to corroborate that the reaction product is isolated from the ionic liquid medium without cross-contamination of the product with the ionic liquid. It could be reached by different ways considering the unique properties of ionic liquids: (i) distillation, (ii) extraction with water or organic solvents and (iii) extraction with supercritical carbon dioxide.

Distillation could be used when the reaction product are not labile since ionic liquid have low vapour pressure. Extraction with water or organic solvent could be used in the case that the ionic liquid was insoluble with the extraction solvent which can be reached by tailoring the hidrophobicity of the ionic liquid changing the anion or the cation composition [19].

However, the use of an organic solvent is not the best option if we pretend an integral ecofriendly system. In order to overcome the disadvantages of using organic solvents for the extraction of reaction products, it has been demonstrated that the extraction of organic compounds from ionic liquids by using supercritical carbon dioxide $\left(\mathrm{scCO}_{2}\right)$ is a promising option.

Meanwhile the $\mathrm{scCO}_{2}$ can be solubilized in the ionic liquid phase, the ionic liquid shows very low solubility in the $\mathrm{scCO}_{2}$ phase. As consequence the $\mathrm{scCO}_{2}$ can extract organic substances from ionic liquids obtaining an extract free of contamination of ionic liquids provided that the ionic liquid is selected in an appropriate way $[20,21]$.

\section{Conclusion and Remarks}

The number of publications related to the application of ionic liquids in biotechnology has increased exponentially during the last 15 years. The next step is the industrial application of the developments achieved. For that, it is essential to consider and address the following aspects: (i) scaling and development of continuous processes under real operating conditions, (ii) deeper study of toxicity and the impact of ionic liquids with the aim to design less toxic and biodegradable ILs which can be applied in industrial process (iii) the study of the costbenefit and the economic and life-cycle analyses of processes.

\section{References}

1. Ruiz A, de los Rios AP, Fernandez FJH, Janssen MHA, Schoevaart R, et al. (2007) Use of ionic liquids as green solvents for extraction of $\mathrm{Zn}^{2+}, \mathrm{Cd}^{2+}$, $\mathrm{Fe}^{3+}$ and $\mathrm{Cu}^{2+}$ from aqueous solutions. Enzyme Microb Technol 40: 1095-1099.

2. De los Rios AP, Fernandez FJH, Rubio M, Gomez D, Villora G (2007) Recent advances in supported ionic liquid membrane technology. J Chem Technol Biotechnol 82: 190-195.

3. Lozano P, Piamtongkam R, Kohns K, de Diego T, Vaultier M (2007) Ionic liquids improve citronellyl ester synthesis catalyzed by immobilized Candida antarctica lipase B in solvent-free media. Green Chem 9: 780-784.

4. Persson M, Bornscheuer UT (2003) Increased stability of an esterase from Bacillus stearothermophilus in ionic liquids as compared to organic solvents. J Mol Catal B Enzym 22: 21-27.

5. Kim MJ, Choi MY, Lee JK (2003) Enzymatic selective acylation of glycosides in ionic liquids: significantly enhanced reactivity and regioselectivity. J Mol Catal 26: 115-118.

6. Fernandez FJH, de los Rios AP, Lozano Blanco LJ, Godinez C (2010) Biocatalytic ester synthesis in ionic liquid media. J Chem Technol Biotechnol 85: 1423-1435.

7. Madeira Lau R, Rantwijk FV, Seddon KR, Sheldon RA (2000) Lipasecatalyzed reactions in ionic liquids. Organic Lett 2: 4189-4191.

8. Lozano P, De Diego T, Carrie D, Vaultier M, Iborra JL (2003) Enzymatic ester synthesis in ionic liquids. J Mol Catal 21: 9-13.

9. Los Rios APD, Fernandez FJH, MartInez FA, Rubio M, Villora G (2007) The effect of ionic liquid media on activity, selectivity and stability of Candida antarctica lipase B in transesterification reactions. Biocatal Biotransform 25: 151-156.

10. Vidya P, Chadha A (2009) The role of different anions in ionic liquids on Pseudomonas cepacia lipase catalyzed transesterification and hydrolysis. J Mol Catal 57: 145-148.

11. Nara SJ, Harjani JR, Salunkhe MM (2002) Lipase-catalysed transesterification in ionic liquids and organic solvents: a comparative study. Tetrahedron Lett 43: 2979-2982.

12. Galai S, de los Rios AP, Fernandez FJH, Kaceman SH, Tomas-Alonso F (2015) Over-activity and stability of laccase using ionic liquids: screening and application in dye decolorization. RSC Adv 5: 16173-16189.

13. Rehmann L, Ivanova E, Ferguson JL, Gunaratne HQN, Seddon KR, et al. (2012) Laccase activity and stability in the presence of menthol-based ionic liquids. Green Chem 14: 725-733.

14. Kacem SH, Galai S, de los Rios AP, Fernandez FJH, Smaali I (2018) New efficient laccase immobilization strategy using ionic liquids for biocatalysis and microbial fuel cells applications. J Chem Technol Biotechnol 93: 174-183.

15. Nara SJ, Mohile SS, Harjani JR, Naik PU, Salunkhe MM (2004) Influence of ionic liquids on the rates and regioselectivity of lipase-mediated biotransformations on 3, 4, 6-tri-O-acetyl-D-glucal. J Mol Catal 28: 39-43.

16. Yuan Y, Bai S, Sun Y (2006) Comparison of lipase-catalyzed enantioselective esterification of ( \pm )-menthol in ionic liquids and organic solvents. Food Chem 97: 324-330.

17. Shah S, Gupta MN (2007) Enhancement of lipase activity in non-aqueous media upon immobilization on multi-walled carbon nanotubes. Biochim Biophys Acta 1770: 94-98.

18. Hernandez-Fernandez FJ, Bayo J, de los Rios AP, Vicente MA, Bernal FJ (2015) Discovering less toxic ionic liquids by using the Microtox ${ }^{\oplus}$ toxicity test. Ecotoxicol Environ Saf 116: 29-33.

19. de los Rios PA, Fernandez FJH, Zapata Henriquez PA, Missoun F (2017) Covalent Immobilization of Cellulase Using Magnetic Poly(ionic liquid) 
Citation: Fernandez FJH (2018) Keys for the Use of lonic Liquids as Reaction Media in Enzyme-Catalyzed Processes. J Bioprocess Biotech 8: e141. doi:10.4172/2155-9821.1000e141

Page 3 of 3

Support: Improvement of the Enzyme Activity and Stability. Chem Eng 5: 6986-6993.

20. Blanchard LA, Gu Z, Brennecke JF (2001) High-Pressure Phase Behavior of Ionic Liquid/CO2 Systems. J Phys Chem 105: 2437-2444.
21. Hernandez FJ, de los Rios AP, Gomez D, Rubio M, Víllora G (2006) A new recirculating enzymatic membrane reactor for ester synthesis in ionic liquid/supercritical carbon dioxide biphasic systems. Appl Catal BEnviron 67: 121-126. 